\title{
The effect of overfeeding newborn rabbits on the rate of skeletal maturation, as determined using a radiographic technique
}

\author{
By S. ANDREW SPENCER*, PHILIP G. SMALL AND DAVID HULL \\ Department of Child Health, University Hospital, Nottingham NG7 $2 U H$
}

(Received 5 March 1984 - Accepted 1 November 1984)

\begin{abstract}
1. Newborn rabbits were overfed by encouraging them to suck from two lactating does. These double-fed rabbits were compared with single-fed litter-mate controls.

2. A standard set of fore- and hind-foot radiographs was obtained by taking daily radiographs from a normal litter and selecting the most representative film to act as a standard for that day.

3. Bone age was assessed in single- and double-fed rabbits at ages 7,14 , and $21 \mathrm{~d}$ by comparing radiographs taken at these ages with the standard films.

4. Double-feeding was associated with an increase in body-weight and an increase in bone age, although the former was increased to a much greater extent than the latter. The advance in bone age was proportional to an increase in bone length.

5. There is little information available on overnutrition and skeletal maturation in man, but what information is available suggests that height and skeletal maturation are increased in parallel. The present study with rabbits supports the concept that overnutrition increases growth rate but does not disturb the relation hetween bone growth and bone age.

6. Bone age can be assessed very sensitively in rabbits using the previously-described technique. It would therefore be a valuable technique for studying the endocrinology of skeletal maturation.
\end{abstract}

When neonatal animals are provided with a high plane of nutrition, growth is accelerated. This has been demonstrated in mice reared in small litters (Parkes, 1926), rats reared in small litters (Widdowson \& McCance, 1960) and rabbits suckled by two lactating does (double-fed) rather than one (Hardman et al. 1970). Accelerated growth does not affect all modalities of growth to an equal extent. In rats (Dickerson \& Widdowson, 1960) and rabbits (Spencer \& Hull, 1984) weight gain is accelerated to a greater extent than growth of the long bones. As a result fast-growing animals are stockier than animals attaining a similar body-weight more slowly. Appleton (1929), investigating the effect of intra-uterine growth rate on skeletal maturation in rabbits, showed that the fetuses that had grown most rapidly had advanced skeletal maturation. Fast-growing rats also have advanced skeletal maturation but, like bone length, it does not increase in parallel to weight gain (Dickerson \& Widdowson, 1960). This suggests that bone length and skeletal maturation may increase in parallel when growth is accelerated by high-plane nutrition. The purpose of the present study is to examine the inter-relations between age, bone age and bone length in normally-fed and double-fed rabbits in order to discover whether bone age and bone length increase in parallel in the double-fed rabbit.

EXPERIMENT A L

\section{Animals, diets and experimental design}

The experiments were conducted on the young from a colony originating from New Zealand White, Californian cross-bred rabbits. Nursing does normally feed their young once daily. Therefore the young can be separated after their first feed and cared for in an incubator, provided they are returned to the mother for approximately $30 \mathrm{~min}$ each morning for feeding.

In these experiments, overfeeding was achieved by introducing the rabbits to a second

* Present address: The Childrens' Hospital, Ladywood Middleway, Birmingham B16 8ET. 


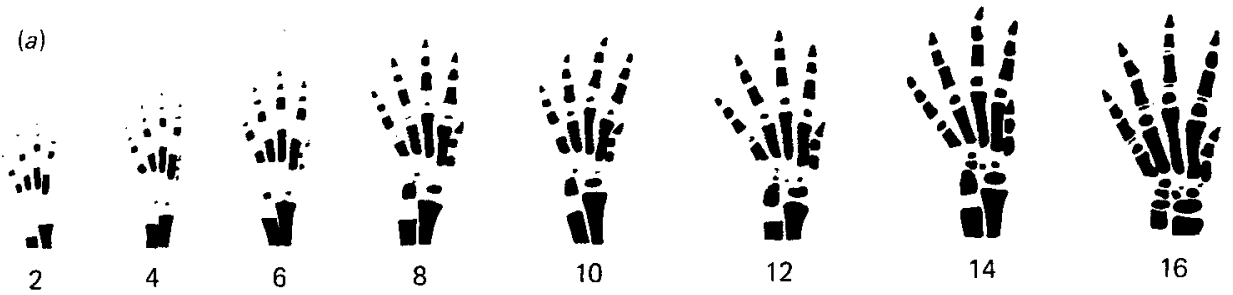

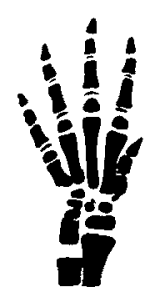

18

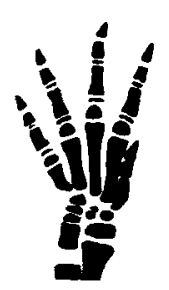

20

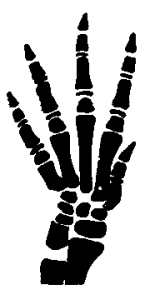

22

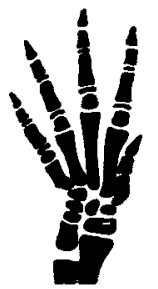

24

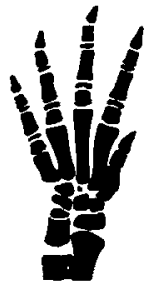

26

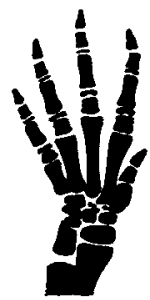

28

$10 \mathrm{~mm}$

(b)

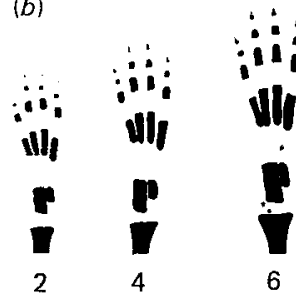

vil
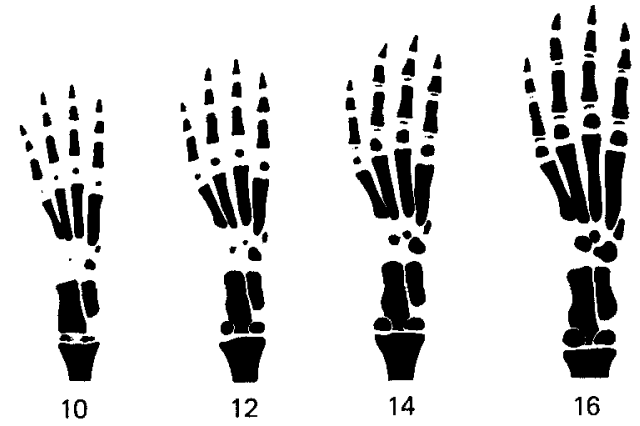

8

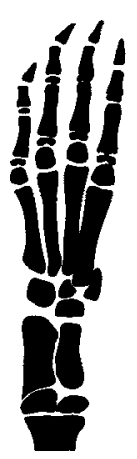

24

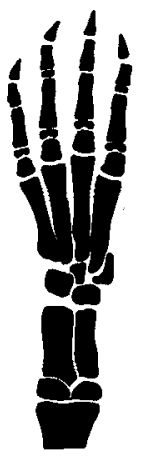

26

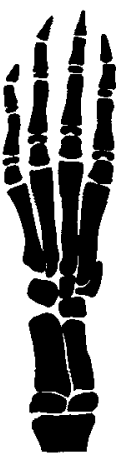

28

$10 \mathrm{~mm}$

Fig. 1. Drawings of standard radiographs of $(a)$ fore-feet, $(b)$ hind-feet, taken on alternate days from ages 2-28 $\mathrm{d}$ in single-fed rabbits. Where bones overlap, the outline of the hidden bone is shown by a thin line. For the sake of clarity, the part of the calcaneus which overlaps the tibia has been omitted. 
lactating doe 8-12 h after they had fed from their own mothers, as first described by Hardman et al. (1970). Rabbits fed in this way will take twice as much milk as their normally-fed litter-mates and are termed 'double-fed'. Litter size was kept to a maximum of six animals and each double-fed rabbit was paired with a litter-mate of similar birth weight, which acted as a single-fed control.

A total of forty-six sets of radiographs were taken of single- and double-fed rabbit pairs at either 7, 14 or $21 \mathrm{~d}$ of age. Fourteen pairs of rabbits were killed after the radiographs were taken, as part of another experiment (Spencer \& Hull, 1984), and it is in these pairs that the length of the humerus was measured to $\pm 0.01 \mathrm{~mm}$ using calipers.

\section{Radiology technique}

A Siemens Garantix 800 falling-load generator with a multix tube (focal spot $0.6 \mathrm{~m}$ ) was used to X-ray the fore- and hind-feet of the rabbits. The live rabbit was hand held and a sheet of clear X-ray film was used to trap the foot that was to be X-rayed gently and hold it in the anatomical position. The X-ray film (CEA non-screen medical X-ray film) was shielded with a sheet of lead rubber except for a window just large enough to contain the rabbit foot, through which the film was exposed. Exposures were taken with an FFD of $900 \mathrm{~mm}, 35 \mathrm{kV}$ and MAS of 80-100. This was found to give a satisfactory resolution of developing bones in rabbits X-rayed on the day after birth and at $28 \mathrm{~d}$ of age.

\section{Estimation of bone age}

A litter of five rabbits from the colony was X-rayed daily for the first $10 \mathrm{~d}$ of life and then on alternate days until the age of $28 \mathrm{~d}$. There was a small degree of variation in the appearance and development of ossification centres within the litter and so the most representative film was selected as a standard for the day. Drawings of the standard film are shown in Fig. 1.

Bone ageing was performed in individual animals by selecting the best match between the test radiograph and the standard film. The shape and structure of the bones were taken into consideration in addition to the presence or absence of ossification centres. Both foreand hind-feet radiographs were matched independently and scored according to the age of the standard film. Where disagreement occurred the mean value was recorded. The scoring was performed blind.

\section{Statistics}

Statistical significance was tested using Student's paired $t$ test.

RESULTS

Double-fed rabbits gained weight more rapidly than single-fed rabbits and were heavier at each of the identified ages (Table 1). Rapid weight gain was associated with an advance

Table 1. Weights of single- and double-fed rabbits at 7, 14 and $21 \mathrm{~d}$ of age

(Mean values and their standard deviations)

\begin{tabular}{|c|c|c|c|c|c|c|}
\hline \multirow[t]{2}{*}{$\begin{array}{l}\text { Age (d)... } \\
\text { No. of rabits... }\end{array}$} & \multicolumn{2}{|c|}{$\begin{array}{r}7 \\
13\end{array}$} & \multicolumn{2}{|c|}{$\begin{array}{l}14 \\
12\end{array}$} & \multicolumn{2}{|c|}{$\begin{array}{l}21 \\
21\end{array}$} \\
\hline & Means & SD & Mean & SD & Mean & SD \\
\hline \multicolumn{7}{|l|}{ Body-wt (g): } \\
\hline Single-fed & 102 & 16 & 178 & 30 & 299 & 51 \\
\hline Double-fed & 159 & 24 & 314 & 38 & 488 & 57 \\
\hline
\end{tabular}


(a)
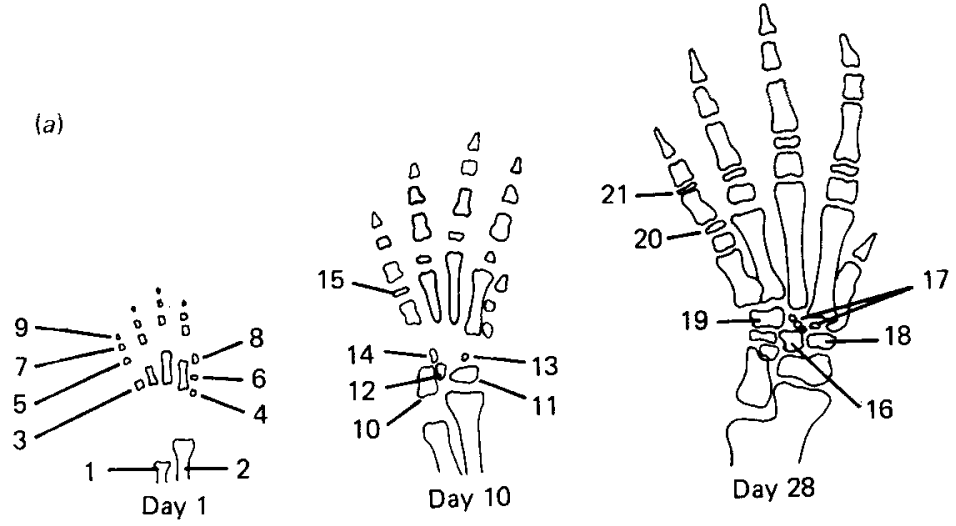

Day 28

(b)

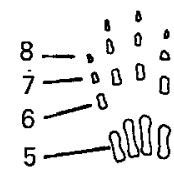

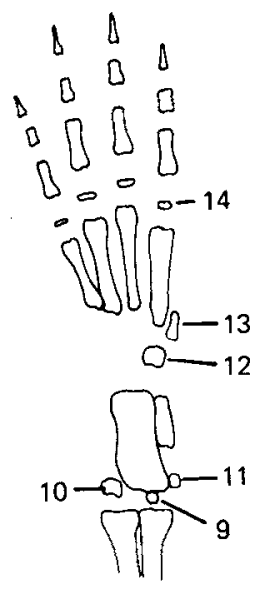

Day 10

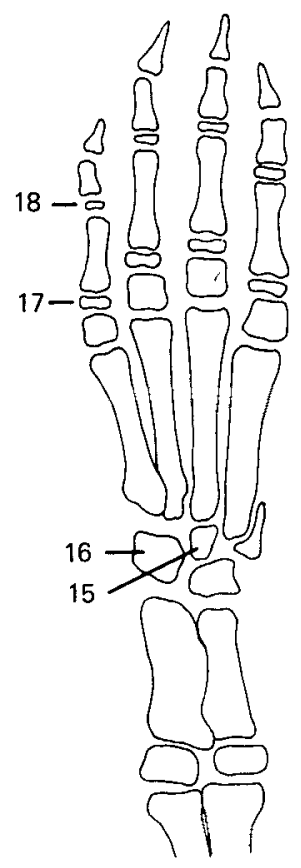

Day 28

Fig. 2. Line drawings of the bones and ossification centres in (a) fore-feet and (b) hind-feet of single-fed rabbits for the purpose of identification.

(a) 1, Ulna; 2, radius; 3, II-V metacarpals; 4, I metacarpals; 5, first phalanges of digits II-V; 6, first phalanges of digit I; 7, second phalanges of digits II $-\mathrm{V} ; 8$, second phalanges of digit I; 9 , third phalanges of digits II-V; 10, distal ulna epiphysis; 11 , distal radial eplphysis; 12 , accessory carpal bone; 13 , radial carpal bone; 14, ulna carpal bone; 15 , epiphysis of II-V metacarpals; 16, intermediate carpal bone; 17 , central + I, II, III carpal bones; 18, epiphysis of first metacarpal; 19, III and IV carpal bones; 20, epiphysis of first phalanges; 21, epiphysis of second phalanges of digits II-V.

(b) 1 , Fibula ; 2 , tibia ; 3, calcaneus; 4, talus; 5 , metatarsals II-IV; 6, first phalanges at digits II-V; 7 , second phalanges at digits II-V; 8 , third phalanges at digits II-V; 9, calcaneal tuber; 10, lateral malleolus; 11 , distal epiphysis of tibia; 12 , central tarsal bone; 13 , metatarsal I; 14, epiphysis of metatarsal II-V; 15, tarsal bone III; 16, IV and V tarsal bones; 17, epiphysis of first phalanges; 18, epiphysis of second phalanges. 


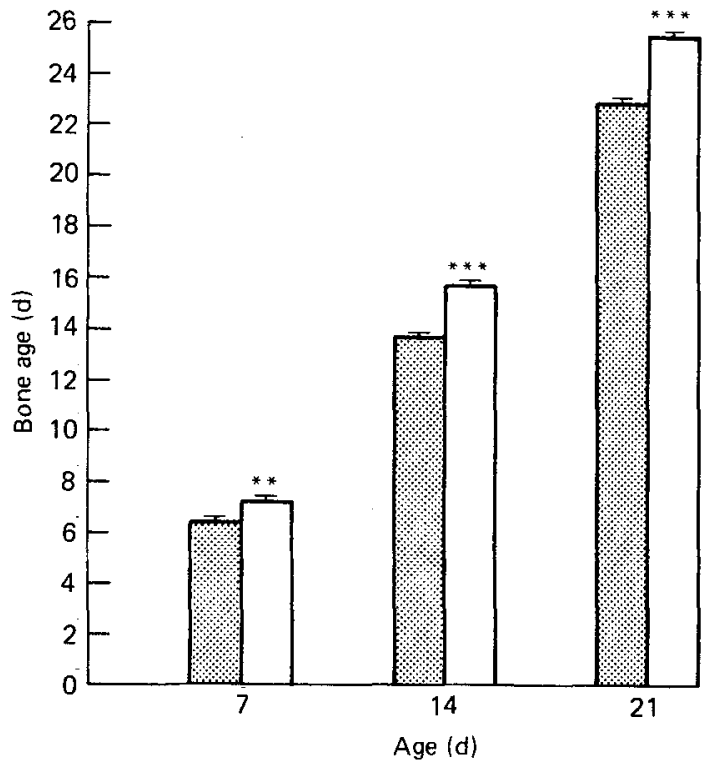

Fig. 3. Mean bone age is shown in (圈) single-fed and ( $\square$ ) double-fed rabbits at 7, 14 and $21 \mathrm{~d}$ of age. The numbers of rabbit pairs examined at each age were thirteen, twelve and twenty-one respectively. Standard deviations are represented by vertical bars. Statistically significant differences between groups: ** $P<0.01, * * * P<0.001$.

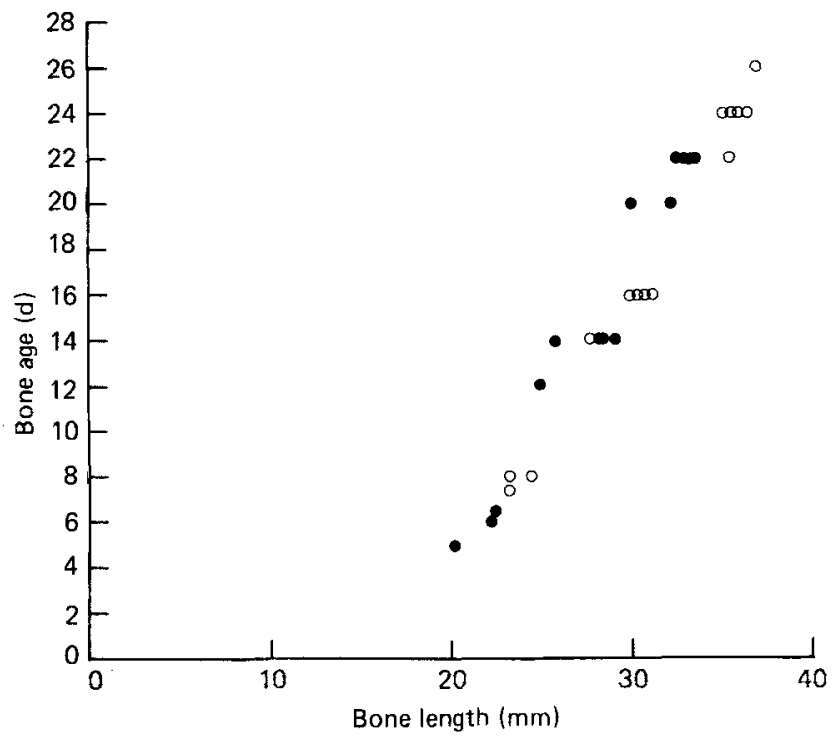

Fig. 4. A linear relation between bone age and bone length is shown in ( $)$ single-fed $(y=13 \cdot 5 x-22 \cdot 9)$ and $(O)$ double-fed $(y=13 \cdot 0 x-23 \cdot 1)$ rabbits. There was no statistically significant difference between the regression equations.

in bone age with respect to chronological age. Individual bones and ossification centres are identified in Fig. 2. The centres that were most obviously advanced in the double-fed rabbits were the metacarpal and metatarsal epiphyses at $7 \mathrm{~d}$ and the epiphysis of the first phalanges (fore- and hind-feet) at $14 \mathrm{~d}$. At $21 \mathrm{~d}$ the carpal bones were advanced in the fore-foot and the metacarpal epiphyses had a more mature shape in the hind-foot. There was a statistical 
difference between the mean bone-age score for single- and double-fed rabbits at each of 7, 14 and $21 \mathrm{~d}$ of age (Fig. 3).

There was a linear relation between bone age and bone length in both single- and double-fed rabbits during the first $21 \mathrm{~d}$ of life (Fig. 4). This relation was similar in single- and double-fed rabbits, indicating that rapid growth does not dissociate the relation between bone growth and bone maturation.

\section{DISCUSSION}

Skeletal development has been described in rabbits using a roetgenographic technique (Nowicki, 1974) but there are no published standards suitable for estimating bone age in individual rabbits. The series of standards that have been presented in the present study do not represent median daily bone development for the colony, as they were derived from one litter only. They do demonstrate a step-wise progression of bone maturation which can be used to quantify differences in maturation between experimental and control animals.

Advance in bone age secondary to a high plane of nutrition has previously been demonstrated in fetal rabbits (Appleton, 1929) and in young, fast-growing rats (Dickerson \& Widdowson, 1960), but a parallel advance in radiologically-determined bone age and bone length has not previously been demonstrated. This close association between advance in bone age and increase in bone length would suggest that single- and double-fed rabbits would have similar bone lengths when mature. Spencer \& Hull (1984) have shown that this is indeed the case.

It is commonly stated in paediatric textbooks (Brook, 1978) that obesity in childhood is associated with an increase in height, which is offset by an increase in skeletal maturation, so that adult height is not affected. Although the results presented here for rabbits would support this concept, there is very little information available in man. There is no doubt that the plane of nutrition in man does affect the rate of skeletal maturation; small-for-date infants have retarded bone age (Kuhns \& Poznanski, 1980) as did children in German orphanages after World War II, who were found to be on insufficient rations (Berridge \& Prior, 1954). Mossberg (1948) reviewed four studies in which skeletal age was assessed in obese children. He concluded that skeletal age was advanced in relation to chronological age. The most interesting of these studies was reported by Bruch (1939) who has published the only results demonstrating a close relation between increased height and advanced skeletal age.

We have demonstrated in rabbits the principle that high-plane nutrition leading to rapid bone growth also leads to an equivalent increase in skeletal maturation so that mature bone length is unaffected. This principle seems to be applicable to man. We have also demonstrated that changes in bone age can be demonstrated daily in young rabbits, using a radiographic technique. This technique would be extremely useful for investigating endocrine influences on skeletal maturation.

\section{REFERENCES}

Appleton, A. B. (1929). Compte Rendu de l'Association des Anatomistes 24, 3-25.

Berridge, F. R. \& Prior, K. M. (1954). Medical Research Council Special Report Series (London) 287, $119-130$.

Brook, C. D. G. (1978). Practical Paediatric Endocrinology, 1st ed. London: Academic Press.

Bruch, H. (1939). American Journal of Diseases in Children 58, 457-484.

Dickerson, J. W. T. \& Widdowson, E. M. (1960). Proceedings of the Royat Society of London (Biology) 152, 207-217.

Hardman, M. J., Hull, D. \& Oyesiku, J. (1970). Biology of the Neonate 16, 306-312.

Kuhns, C. R. \& Poznanski, A. K. (1980). Critical Reviews in Diagnostic Imaging 12, $245-308$. 
Mossberg, H. (1948). Acta Paediatrica Scandinavica Suppl II, 31-35.

Nowicki, M. (1974). Folia Morphologica (Warsz) 33, 67-79.

Parkes, A. S. (1926). Annales of Applied Biology 13, 374-394.

Spencer, S. A. \& Hull, D. (1984). British Journal of Nutrition 51, 389-402.

Widdowson, E. M. \& McCance, R. A. (1960). Proceedings of the Royal Society of London (Biology) 152, $188-206$. 